\title{
Single amino acid sequence polymorphisms in rat cardiac troponin revealed by top-down tandem mass spectrometry
}

\author{
Raquel Sancho Solis $\cdot$ Ying Ge $\cdot$ Jeffery W. Walker
}

Received: 21 November 2008/Accepted: 6 January 2009/Published online: 23 January 2009

(C) The Author(s) 2009. This article is published with open access at Springerlink.com

\begin{abstract}
Heterotrimeric cardiac troponin (cTn) is a critical component of the thin filament regulatory complex in cardiac muscle. Two of the three subunits, cTnI and cTnT, are subject to post-translational modifications such as proteolysis and phosphorylation, but linking modification patterns to function remains a major challenge. To obtain a global view of the biochemical state of cTn in native tissue, we performed high resolution top-down mass spectrometry of cTn heterotrimers from healthy adult rat hearts. cTn heterotrimers were affinity purified, desalted and then directly subjected to mass spectrometry using a 7 Tesla Thermo LTQ-FT-ICR instrument equipped with an ESI source. Molecular ions for N-terminally processed and acetylated cTnI and cTnT were readily detected as were other post-translationally modified forms of these proteins. cTnI was phosphorylated with a distribution of un-, monoand bisphosphorylated forms of $41 \pm 3 \%, 46 \pm 1 \%$, $13 \pm 3 \%$, respectively. cTnT was predominantly monophosphorylated and partially proteolyzed at the $\mathrm{Glu}^{29}-\mathrm{Pro}^{30}$
\end{abstract}

R. Sancho Solis · Y. Ge · J. W. Walker

Department of Physiology, University of Wisconsin-Madison,

Madison, WI 53706, USA

Y. Ge

Human Proteomics Program, University of Wisconsin-Madison, Madison, WI 53706, USA

J. W. Walker

Department of Physiology, University of Arizona, Tucson, AZ 85724, USA

\section{J. W. Walker $(\bowtie)$}

Molecular Cardiovascular Research Program, Arizona Diabetes Program, MRB 411, University of Arizona College of Medicine, 1656 E Mabel Ave., Tucson, AZ 85724, USA

e-mail: jwwalker@arizona.edu peptide bond. Also observed in high resolution spectra were 'shadow' peaks of similar intensity to 'parent' peaks exhibiting masses of cTnI+16 Da and cTnT+128 Da, subsequently shown by tandem mass spectrometry (MS/ MS) to be single amino acid polymorphisms. Intact and protease-digested cTn subunits were fragmented by electron capture dissociation or collision activated dissociation to localize an Ala/Ser polymorphism at residue 7 of cTnI. Similar analysis of cTnT localized an additional Gln within a three residue alternative splice site beginning at residue 192. Besides being able to provide unique insights into the global state of post-translational modification of cTn subunits, high resolution top-down mass spectrometry readily revealed naturally occurring single amino acid sequence variants including a genetic polymorphism at residue 7 in cTnI, and an alternative splice isoform that affects a putative hinge region around residue 192 of cTnT, all of which co-exist within a single rat heart.

Keywords Phosphorylation - Alternative splicing ·

Proteomics · Post-translational modification ·

Electron capture dissociation

\section{Introduction}

The heterotrimeric protein troponin $(\mathrm{cTn})$ together with tropomyosin $(\mathrm{Tm})$ make up the thin filament associated $\mathrm{Ca}^{2+}$ regulatory switch in cardiac muscle (Solaro 2008). Two subunits of the cTn complex, cTnI and cTnT, are widely used in clinical medicine as biomarkers of cardiac injury (Jaffe et al. 2006). Moreover, cTn subunits have received considerable attention as sarcomeric protein genes harboring mutations that cause familial hypertrophic cardiomyopathy (HCM) in humans (Harada and Morimoto 
2004). cTnI and cTnT are known to be key substrates for regulatory kinases including protein kinase $\mathrm{A}$, protein kinase $\mathrm{C}$ and many others (Pi et al. 2002, 2003; Sumandea et al. 2003; Vahebi et al. 2005; Solaro 2008). Proteolytic cleavage of troponin subunits has also been suggested to contribute to cardiac syndromes such as myocardial stunning and chronic heart failure (Murphy 2006).

Traditional strategies for establishing the state of posttranslational modification of cTn rely on ${ }^{32} \mathrm{P}$-incorporation, tryptic peptide mapping (Jideama et al. 1996), and western blotting using antibodies to known phosphoserine and phosphothreonine epitopes (Kobayashi et al. 2005; Wang et al. 2006; Messer et al. 2007). These strategies can be quite specific and relatively quantitative, but they seldom provide a global (i.e. comprehensive) view of the chemical state of these critical proteins. Developments in chromatography and mass spectrometry (MS) have dramatically improved the ability to identify peptides and localize protein modifications in a controlled proteolytic digest with sub-dalton mass accuracy (i.e. the 'bottom-up' approach; Nesviszhsii et al. 2007). Unfortunately, this strategy is also not comprehensive because some regions of the protein are not represented in the peptide digest (sequence coverage is incomplete) and quantification of peptides in a mixture remains a significant challenge. Moreover, with digestion the 'connectivity' between modified peptides from different regions of the protein is lost, further precluding a comprehensive understanding of protein modifications, particularly those that may be inter-dependent.

Mass analysis of intact proteins (i.e. the 'top-down' approach) offers the promise of a global assessment of posttranslational modifications and point mutations, including the localization of protein modifications with nearly complete sequence coverage (Ge et al. 2002; Han et al. 2006; Kelleher et al. 1999; Siuti and Kelleher 2007; Zabrouskov et al. 2008). The top-down strategy starts with highly accurate molecular weight measurements of intact proteins followed by fragmentation in the mass spectrometer of a protein of interest by electron capture dissociation (ECD) (McLafferty et al. 2001) or collisionally activated dissociation (CAD) (Senko et al. 1994), and accurate mass analysis of the ensuing fragments to obtain primary sequence information.

With the goal of obtaining a more complete view of the chemical state of cTn subunits in native tissues, we report here a strategy involving: (i) affinity purification of whole troponin complexes (containing cTnI, cTnT and cTnC) from a single rat heart (Messer et al. 2007) followed by (ii) high resolution tandem mass spectrometry of the entire complex without protease digestion (Zabrouskov et al. 2008). As expected, this strategy provides novel insights into post-translational modification of $\mathrm{cTnI}$ and $\mathrm{cTnT}$ including $\mathrm{N}$-terminal processing, phosphorylation and proteolysis. Unexpectedly, the technique also revealed single amino acid sequence polymorphisms in both cTnI and cTnT in normal healthy rat hearts. The polymorphisms were shown to be an Ala to Ser substitution in residue 7 of cTnI, and a likely alternative splice variant that affects a putative hinge region of cTnT around residue 192. Some of this data has been presented in preliminary form to the American Biophysical Society (Sancho Solis et al. 2009).

\section{Experimental procedures}

\section{Materials}

All reagents were obtained from Sigma Chemical Co (St Louis, MO, USA) unless noted otherwise. Complete protease inhibitor cocktail, trypsin (Sequencing grade, modified), Lys-C (Endoproteinase Lys-C) or Glu-C (Endoproteinase Glu-C) were from Roche (Mannheim, Germany).

\section{Affinity purification of $\mathrm{cTn}$}

All procedures were approved by the University of Wisconsin Animal Care and Use Committee. Whole cTn complexes were affinity purified by the method of Messer et al. (2007) with modifications. Briefly, hearts were surgically excised from adult male Sprague-Dawley rats anesthetized with isoflurane and rapidly washed with ice-cold Ringer's solution $(125 \mathrm{mM} \mathrm{NaCl}, 5 \mathrm{mM} \mathrm{KCl}, 25 \mathrm{mM}$ HEPES$\mathrm{NaOH}$ pH 7.4, $2 \mathrm{mM} \mathrm{NaH} \mathrm{PO}_{4}, 1.2 \mathrm{mM} \mathrm{MgSO}_{4}, 5 \mathrm{mM}$ Pyruvate and $11 \mathrm{mM}$ D-glucose) to remove blood. Ventricular tissue was homogenized for 4-6 s in relaxing solution $\left(100 \mathrm{mM} \mathrm{KCl}, 10 \mathrm{mM}\right.$ Imidazole, $6 \mathrm{mM} \mathrm{MgCl}_{2}$, $2 \mathrm{mM}$ EGTA, $5 \mathrm{mM}$ ATP, $1 \mathrm{mM}$ PMSF, $1 \mathrm{mM}$ DTT, $10 \mathrm{mM}$ Benzamidine and $0.75 \mathrm{mg} / \mathrm{ml}$ protease inhibitor cocktail) using a Polytron homogenizer. Cell fragments were skinned (chemically permeabilized) in relaxing solution containing $0.33 \%$ Triton-X-100 and $0.5 \mathrm{mg} / \mathrm{ml}$ BSA for $4 \mathrm{~min}$, washed twice then incubated in extraction solution $(0.7 \mathrm{M} \mathrm{LiCl}, 25 \mathrm{mM}$ Tris $\mathrm{pH}$ 7.5, $5 \mathrm{mM}$ EGTA, $0.1 \mathrm{mM} \mathrm{CaCl}_{2}, 5 \mathrm{mM}$ DTT, $1 \mathrm{mM}$ PMSF and $0.75 \mathrm{mg} / \mathrm{ml}$ protease inhibitor cocktail) for $1 \mathrm{~h}$ at $4^{\circ} \mathrm{C}$. Cell debris was removed by centrifugation at 55,000 rpm for $45 \mathrm{~min}(80 \mathrm{Ti}$ rotor, Beckman L-55 ultracentrifuge). The supernatant was incubated with $0.3 \mathrm{ml}$ of CNBr-activated Sepharose CL-4B conjugated with a monoclonal cTnI antibody (anti-troponin I monoclonal antibody MF4, Hytest, Finland) for $1 \mathrm{~h}$ at $4{ }^{\circ} \mathrm{C}$ and then loaded into an empty disposable column. After washing with 5 column volumes of extraction solution, the column was eluted with $50 \mathrm{mM}$ glycine $\mathrm{pH} 2$ while $0.4 \mathrm{ml}$ fractions were collected and neutralized immediately by $80 \mu \mathrm{l}$ of $1 \mathrm{M}$ MOPS pH 9. Fractions were analyzed for protein content by SDS-PAGE on $15 \%$ gels stained with 
Coomassie Blue. Typically, four eluted fractions contained cTn subunit bands at $17 \mathrm{kDa}(\mathrm{cTnC}), 27 \mathrm{kDa}(\mathrm{cTnI})$ and $34 \mathrm{kDa}(\mathrm{cTnT})$, with fraction 2 showing the darkest bands and most consistent 1:1:1 stoichiometry (Fig. 1).

\section{Top-down mass spectrometry}

Immunoaffinity purified rat $\mathrm{cTn}$ complexes were desalted using an offline reverse phase $\mathrm{C} 18$ protein microtrap (Michrom Bioresources, Inc, CA), eluted first with $1 \%$ acetic acid in 50:50 methanol:water and then $1 \%$ acetic acid in 75:25 methanol:water. Samples were introduced to the mass spectrometer using an automated chip-based nanoESI source (Triversa NanoMate, Advion BioSciences, Ithaca, NY) with a spray voltage of $1.4-1.6 \mathrm{kV}$ versus the inlet of the mass spectrometer, resulting in a flow of 50$200 \mathrm{nl} / \mathrm{min}$. Protein molecular ions were analyzed using a linear trap/FTICR (LTQ FT Ultra) hybrid mass spectrometer (Thermo Scientific Inc., Bremen, Germany). Ion transmission into the linear trap (LT) and subsequently into the FTICR cell was automatically optimized for maximum ion signal. The number of accumulated ions for the full scan LT, FTICR cell (FT), MS ${ }^{\mathrm{n}}$ FTICR cell and ECD were $3 \times 10^{4}, 9 \times 10^{6}, 8 \times 10^{6}$ and $5 \times 10^{6}$, respectively. The resolving power of the FTICR mass analyzer was typically set at 200,000 resulting in an acquisition rate of $1 \mathrm{scan} / \mathrm{s}$. Charge states of protein molecular ions were first isolated and then dissociated by ECD using 2-3\% "electron energy" and a $45-150 \mathrm{~ms}$ duration with no delay. Isolated charge states were also dissociated by CAD using collision energies in the range of 10-22\%. Typically, 500-3,000 transients were averaged to ensure high quality ECD or

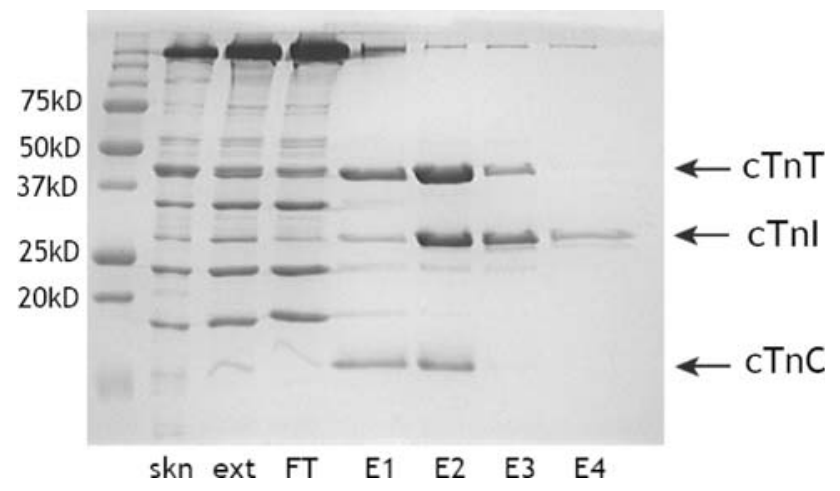

Fig. 1 Affinity purification of cTn complexes from a single rat heart. A representative 15\% SDS-PAGE gel stained with Coomassie Blue. Each lane represents different stages of the purification procedure: $s k n$ skinned cardiac myofibrils; ext extracted cardiac contractile proteins; FT column flow through; and E1-E4 fractions 1-4 collected during low pH elution. Labels indicate apparent MW of markers (left) and positions of cTnT, cTnI and cTnC (right). Weak Coomassie staining of $\mathrm{TnC}$ has been documented by others (Yates and Greaser 1983)
CAD spectra. All FTICR spectra were processed with Xtract Software (FT programs 2.0.1.0.6.1.4, Xcallibur 2.0.5, Thermo Scientific Inc., Bremen, Germany) using a signal to noise threshold of 2 and fit factor of $40 \%$, and then validated manually. The resulting mass lists were further assigned using in-house "Ion Assignment" software (Version 1.0) based on the protein sequence of rat cTnI and cTnT obtained from Swiss-Prot protein knowledgebase (primary accession numbers P23693 and P50753 isoform 2, respectively). Allowance was made for possible post-translational modifications such as removal of initial Met, acetylation of the N-terminus and variable phosphorylation sites, using a $0.1 \mathrm{Da}$ tolerance for precursor and fragment ions. All reported $\mathrm{M}_{\mathrm{r}}$ values are most abundant masses.

\section{Bottom-up mass spectrometry}

Immunoaffinity purified cTn complexes were reduced and alkylated by incubation in $20 \mathrm{mM}$ DTT for $10 \mathrm{~min}$ at $95^{\circ} \mathrm{C}$, followed by incubation with $50 \mathrm{mM}$ iodoacetic acid for $30 \mathrm{~min}$ at $37^{\circ} \mathrm{C}$. After $\mathrm{pH}$ was adjusted to 8.0 by addition of $50 \mathrm{mM}$ bicarbonate, samples were incubated with trypsin, Lys-C or Glu-C at a final ratio of 1:20 to 1:50 protease to protein by weight and incubated overnight at $25^{\circ} \mathrm{C}$ or $37^{\circ} \mathrm{C}$. The reaction was terminated by addition of $4 \mu \mathrm{l}$ of acetic acid. The resulting peptide mixture was desalted using an offline reverse phase $\mathrm{C} 18$ peptide microtrap (Michrom Bioresources, Inc., CA) and analyzed using a linear trap/ FTICR (LTQ FT Ultra) hybrid mass spectrometer (Thermo Scientific Inc., Bremen, Germany). Individual charge states of candidate peptides were isolated and dissociated by ECD (3-5\% "electron energy" and 75-150 ms duration with no delay) or CAD (12-25\% collisional energies).

\section{Results}

Affinity purified cTn from adult rat heart showed three major bands on Coomassie stained SDS-PAGE gels with the expected molecular sizes of 17, 27 and $34 \mathrm{kDa}$ (Fig. 1). Mass spectrometry analysis of these purified protein preparations consistently revealed complex charge state envelopes and isotope patterns from which assignments were made for full length cTnI (Fig. 2) and cTnT (Fig. 5). Mass peaks for cTnC were seldom observed for reasons that are not yet known. For cTnI, a strong signal was observed for a species with most abundant mass of 24,069.72 Da which matched rat cTnI with the initial Met removed and the new N-terminal Ala acetylated. Species were also readily observed that matched this $\mathrm{N}$-terminally processed cTnI containing either one or two covalently bound phosphoryl moieties (i.e. $+80 \mathrm{Da}$ and $+160 \mathrm{Da}$ ). 
The intensity ratio for $\mathrm{cTnI}$ in its unphosphorylated (cTnI), monophosphorylated (cTnI-P) and bisphosphorylated (cTnI-PP) states averaged over spectra from 11 hearts was $41 \pm 3 \%, 46 \pm 1 \%, 13 \pm 3 \%$, respectively (Fig. 2).

The monophosphorylated species of cTnI (cTnI-P) was isolated in the mass spectrometer and subjected to ECD fragmentation to localize the phosphorylated residue(s). Fragmentation patterns revealed that the vast majority of phosphorylation in cTnI-P was at one of the two PKA phosphorylation sites, $\operatorname{Ser}^{22}$ or $\operatorname{Ser}^{23}$ (Fig. 3). A definitive localization to one of these sites was not possible because the key fragmentation event between $\operatorname{Ser}^{22}$ and $\operatorname{Ser}^{23}$ was not consistently observed. Further analysis of $\mathrm{N}$-terminal
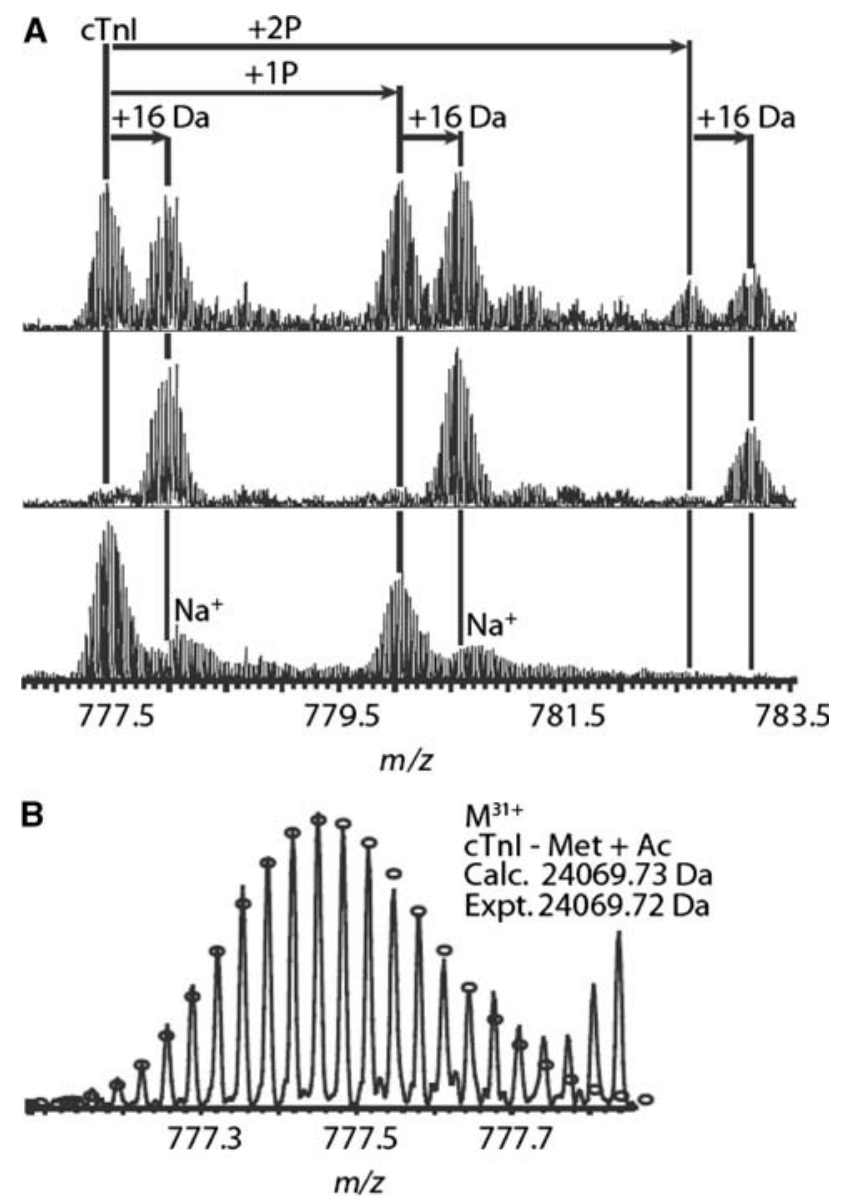

Fig. 2 cTnI isoforms in rat heart. a ESI/FTMS spectrum of cTnI protein ions from a rat expressing both $\mathrm{cTnI}$ and a cTnI+16 Da variant in unphosphorylated, monophosphorylated $(+1 \mathrm{P})$ and biphosphorylated $(+2 \mathrm{P}$ ) states (top panel). ESI/FTMS spectra of cTnI proteins ions expressing only one of the cTnI variants in its phosphorylated states (middle and bottom panels). b Isotopically resolved cTnI molecular ion in the +31 charge state $\left(\mathrm{M}^{31+}\right)$. Circles represent the theoretical abundance isotopic distribution for cTnI (Swiss-Prot TNNI3_RAT, primary accession number P23693) with calculated most abundant mass for cTnI-Met+acetyl of $24069.73 \mathrm{Da}$ corresponding to the experimental most abundant mass of $24069.72 \mathrm{Da}$. $\mathrm{Na}^{+}$indicates sodium ion adducts of primary peaks at $+22 \mathrm{Da}$ peptides generated by 'in solution' trypsin digestion of cTn complexes did, however, place a phosphoryl moiety predominantly at $\operatorname{Ser}^{22}$ (data not shown), consistent with a previous analysis of human cTnI (Zabrouskov et al. 2008).

In some preparations, a striking pattern of 'parent' and 'shadow' peaks of nearly identical intensity was observed with masses equivalent to cTnI and cTnI+16 Da including un-, mono- and bisphosphorylated forms of each (Fig. 2a). In other preparations, only one set of these peaks was observed: the 'parent' peaks at cTnI, cTnI-P and cTnI-PP, or the corresponding 'shadows' peaks at $\mathrm{cTnI}+16$, cTnI$\mathrm{P}+16$ and cTnI-PP+16 Da (Fig. 2a). Out of 11 total hearts analyzed, an equal mixture of 'parent' and 'shadow' peaks occurred in seven hearts, parent peaks alone occurred in one heart, and shadow peaks alone occurred in three hearts. Isolation and fragmentation of the cTnI+16 $\mathrm{Da}$ peak revealed a +16 Da difference within the first 20 residues of cTnI (Fig. 3). Further localization of this modification was achieved by trypsin digestion to generate peptide fragments that could be further sequenced by MS/MS (Fig. 4). This analysis localized the $16 \mathrm{Da}$ difference to residue 7 of cTnI, placing an Ala or a Ser at this position. This sequence polymorphism may have an impact on the extent of cTnI phosphorylation as the $\mathrm{Ser}^{7}$ variant tended to display more phosphorylation than the $\mathrm{Ala}^{7}$ variant (Fig. 2a), but resolving this issue will require further investigation.

For cTnT, a strong signal was observed for a species with mass of 34,442.44 Da which matched rat cTnT (adult isoform 2) with the initial Met removed, the new N-terminal Ser acetylated, and a single covalently bound phosphoryl moiety (+80 Da) (Fig. 5). Unphosphorylated cTnT represented $10 \%$ of the total intensity of intact cTnT indicating that the majority of cTnT was constitutively monophosphorylated (cTnT-P), possibly on a single site as bisphosphorylated cTnT was not detected. A major protein ion was also detected with mass of 30,950.17 Da (Fig. 5) and subsequently shown by ECD to be a cTnT fragment consisting of residues Pro $^{30}$ to $\mathrm{Lys}^{288}$. Specifically, isolation and ECD fragmentation of the $\mathrm{M}^{38+}$ peak at 30,950.17 Da produced $7 c$-ions that matched the N-terminus of cTnT30-288 $\left(c_{17}^{2+}, c_{20}^{2+}, c_{21}^{2+}, c_{32}^{3+}, c_{52}^{6+}, c_{59}^{7+}\right.$ and $\left.c_{60}^{7+}\right)$ and $40 z$-ions that matched its $\mathrm{C}$-terminus (data not shown). Importantly, this cTnT30-288 fragment was not N-terminally acetylated (nor were any of its ECD generated $c$-ions) suggesting that it arose through proteolysis rather than via a secondary transcription/translation start site or via alternative mRNA splicing (see section "Discussion"). cTnT30-288 was also not phosphorylated suggesting that full length cTnT-P was phosphorylated within the first 29 residues of its $\mathrm{N}$-terminus. ECD fragmentation of intact cTnT-P further indicated that there was no detectable phosphorylation between $\operatorname{Ser}^{198}$ and the C-terminus, thereby ruling out significant basal phosphorylation of PKC 
Fig. 3 Top-down MS/MS analysis of monophosphorylated cTnI+16 Da variant. a ECD spectrum of molecular ion at $\mathrm{m} /$ z 834.3. b Cleavage assignments of the ECD spectrum as in A mapped onto the cTnI sequence (Swiss-Prot primary accession number P23693). Phosphorylated ions labeled " $p$ " in the ECD spectrum.

Monophosphorylation localized to the $\mathrm{Ser}^{22 / 23}$ cluster indicated by a "p" in the protein sequence. * indicates ions detected with $+16 \mathrm{Da}$
A

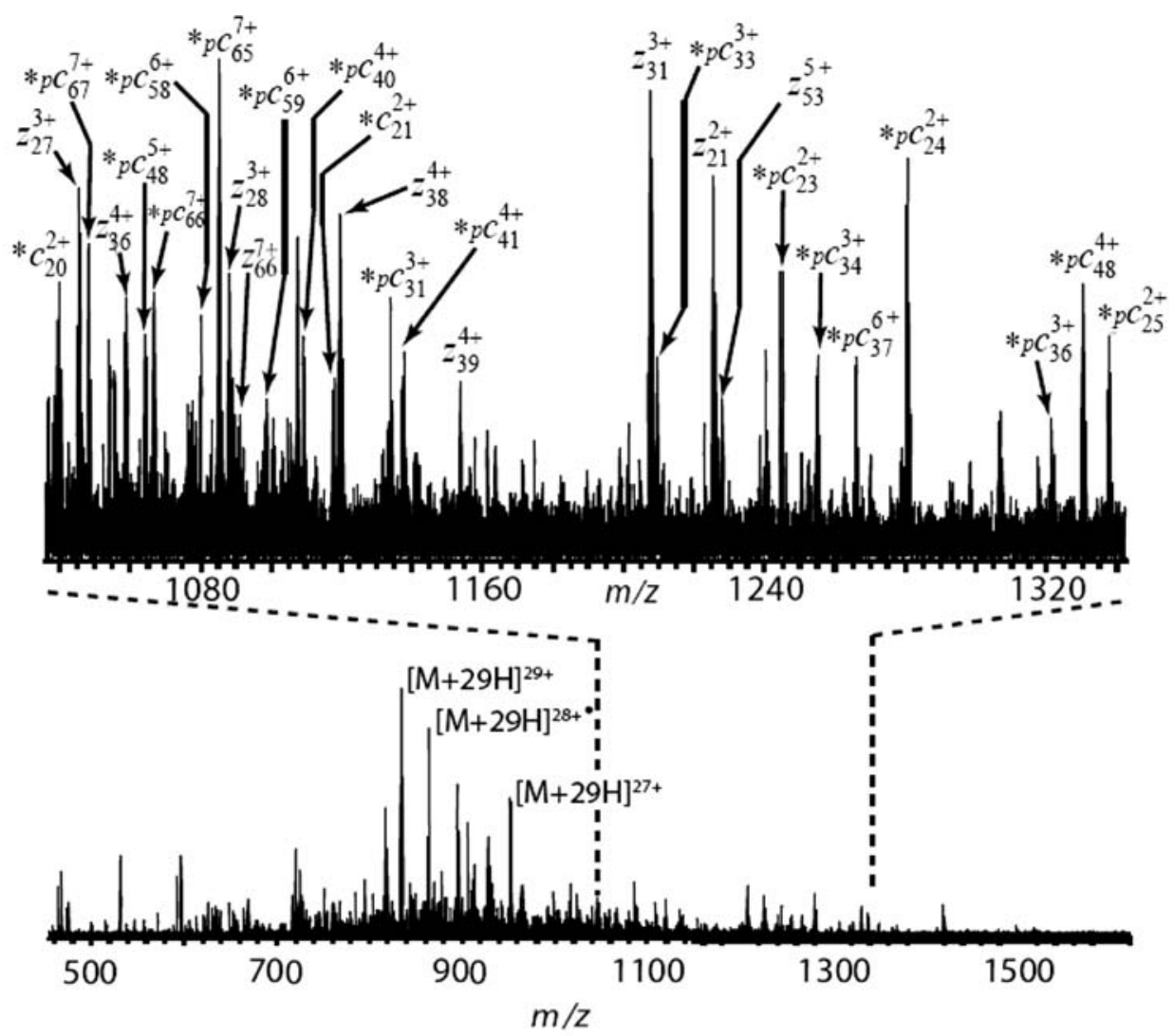

B

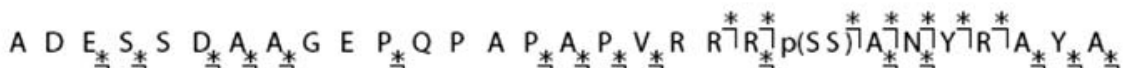

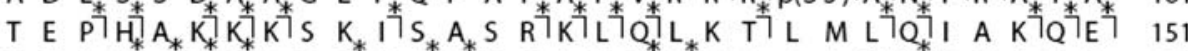

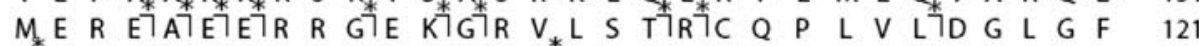 ETE L Q D L C R Q L H A R V D KK VLD ELE R Y D V E A K K V T K 91

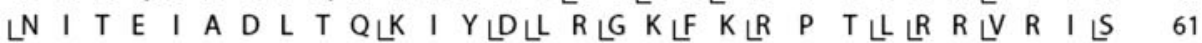

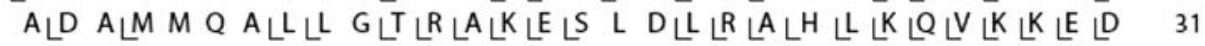

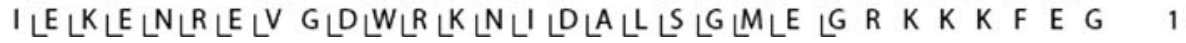

sites $\operatorname{Ser}^{198}$ and $\mathrm{Thr}^{203}$ (data not shown). However, topdown ECD and protease digestion of cTnT-P both failed to narrow down phosphorylation site(s) further, possibly due to the highly acidic nature of the N-terminus of cTnT.

Another major peak was observed with extensive sequence similarity to cTnT-P, but differed in its overall mass by $128 \mathrm{Da}$ (Fig. 5a). Addition or subtraction of C-terminal Lys (equivalent to $128 \mathrm{Da}$ ) was ruled out by numerous ECD generated $z$-ions that revealed retention of a single C-terminal Lys. Moreover, the ECD data clearly showed that the $128 \mathrm{Da}$ addition was not contained between $\mathrm{Ser}^{198}$ and the C-terminus of cTnT. Glu-C digestion was then employed to generate candidate peptides that contained the +128 Da mass difference. Two peptides were observed that matched the mass of an internal cTnT peptide at $\mathrm{Ala}^{173}$ to $\mathrm{Glu}^{195}$ and $\mathrm{Ala}^{173}$ to $\mathrm{Glu}^{195}+128 \mathrm{Da}$ (Fig. 6). The two peptides were isolated and subjected to MS/MS by CAD. Indeed, one peptide matched the sequence of a 23 amino acid peptide from residues 173 to 195 of cTnT (Fig. 6a). The other peptide matched the sequence of a 24 amino acid peptide with an extra $128 \mathrm{Da}$ at residue 20 (Fig. 6b). Therefore, the tandem MS/MS data of these peptides placed an extra Lys or Gln at residue 20 of this peptide, equivalent to residue 192 of full length rat cTnT (Fig. 6). As described in the section "Discussion," these observations can be accounted for by the presence of two alternatively spliced variants of cTnT that include or delete a Gln at position 192 of the protein sequence.

\section{Discussion}

In this study we describe a high resolution top-down mass spectrometry strategy to examine the biochemical state of cardiac troponin (cTn) subunits isolated from rat heart. Affinity chromatography with a well-characterized monoclonal antibody resin was employed to rapidly purify cTn complexes from rat heart homogenates. The entire 
Fig. 4 Identification of Ala or Ser at position 7 in cTnI by bottom-up mass spectrometry. Precursor ions (insets) and their CAD spectra are illustrated for $\mathrm{N}$-terminal tryptic peptides $\left(\mathrm{A}^{1}\right.$ $\mathrm{R}^{19}$, sequences shown) obtained by digestion of purified cTn complexes. a cTnI Ala $^{1}-\mathrm{Arg}^{19}$ with $\mathrm{Ala}^{7}$. b cTnI Ala ${ }^{1}-\mathrm{Arg}^{19}$ with $S^{7}$. Similar results were obtained with $\mathrm{N}$-terminal tryptic peptides $\mathrm{Ala}^{1}-\operatorname{Arg}^{20}$ (not shown)

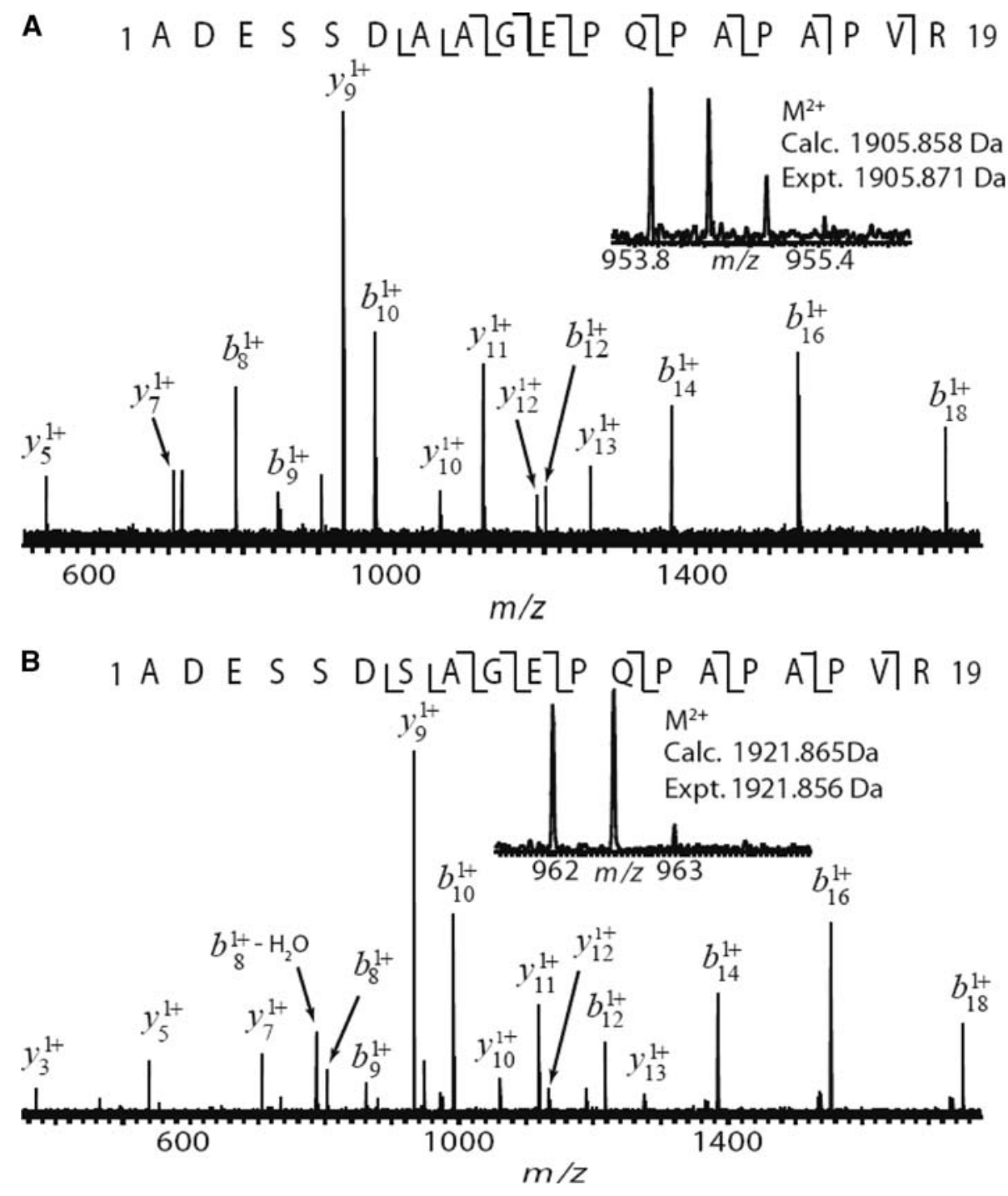

complex, after desalting, was then subjected to mass spectrometry to reveal masses of intact cTnI and cTnT, as well as prominent post-translationally modified forms. The use of high resolution top-down mass spectrometry offered significant advantages for the identification and quantification of single amino acid sequence variants of the cTn subunits. Also key to the analysis was peptide backbone fragmentation in the gas phase by ECD and CAD, in combination with 'in solution' proteolytic digestion that allowed for extensive peptide/protein sequencing, and thus for precise localization of observed sequence heterogeneities and other modifications.

An apparent genetic polymorphism was observed here at the protein level for cTnI expressed in Sprague-Dawley rat hearts. This polymorphism has been detected previously at the mRNA level by sequence analysis of rat heart cDNA clones (Martin and Orlowski 1991). We confirm here that the polymorphism at position 7 of rat cTnI occurs at the protein level and within a single heart. The functional significance of this apparent 'allelic' polymorphism remains an open question.

Monophosphorylated cTnI was predominantly phosphorylated on $\mathrm{Ser}^{22}$, the $\mathrm{N}$-terminal side of the vicinal $\mathrm{Ser}^{22 / 23}$ pair targeted by protein kinase $\mathrm{A}$. This result is similar to what was observed in a top-down mass spectrometry analysis of human cTnI (Zabrouskov et al. 2008). In that study, preferential phosphorylation of $\mathrm{Ser}^{22}$ was interpreted to indicate that phosphor-Ser ${ }^{22}$ is the thermodynamically favored site in vivo, despite the fact that the $\mathrm{Ser}^{23}$ site (the C-terminal side of the pair) appears to be kinetically favored by protein kinase A in vitro (Jaquet et al. 1995; Zhang et al. 1995; Keane et al. 1997; Sancho Solis and Walker unpublished). This apparent paradox can be accounted for by assuming that in vivo a phosphatase complementary to the kinase dephosphorylates $\mathrm{Ser}^{23}$ more quickly than $\mathrm{Ser}^{22}$. In such a system, $\mathrm{Ser}^{22}$ would behave as the more stable (but still slowly turning over) site of modification, while $\mathrm{Ser}^{23}$ would turn over much more 
Fig. 5 cTnT isoforms in rat heart. a ESI/FTMS spectrum of cTnT protein ions displaying cTnT and a cTnT+128 Da variant in unphosphorylated and monophosphorylated $(+1 \mathrm{P})$ states, as well as an unphosphorylated cTnT30-288 proteolytic fragment.

b Isotopically resolved molecular ions of $\mathrm{M}^{42+}$ monophosphorylated cTnT (left) and $\mathrm{M}^{38+}$ cTnT30-288 (right). Circles represent the theoretical abundance of the isotopic distribution for cTnT (Swiss-Prot TNNT2_RAT, primary accession number P50753-2) with calculated most abundant mass for cTnT$\mathrm{Met}+$ acetyl $+\mathrm{P}$ of 34442.41 Da corresponding to the experimental most abundant mass of $34442.44 \mathrm{Da}$ (left). The same TNNT2_RAT protein sequence was used to calculate most abundant mass for cTnT30-288 without modifications (no acetyl, no P) of 30950.14 Da corresponding to the experimental most abundant mass of $30950.17 \mathrm{Da}$ (right). $\mathrm{Na}^{+}$indicates sodium adducts of primary peaks at $+22 \mathrm{Da}$

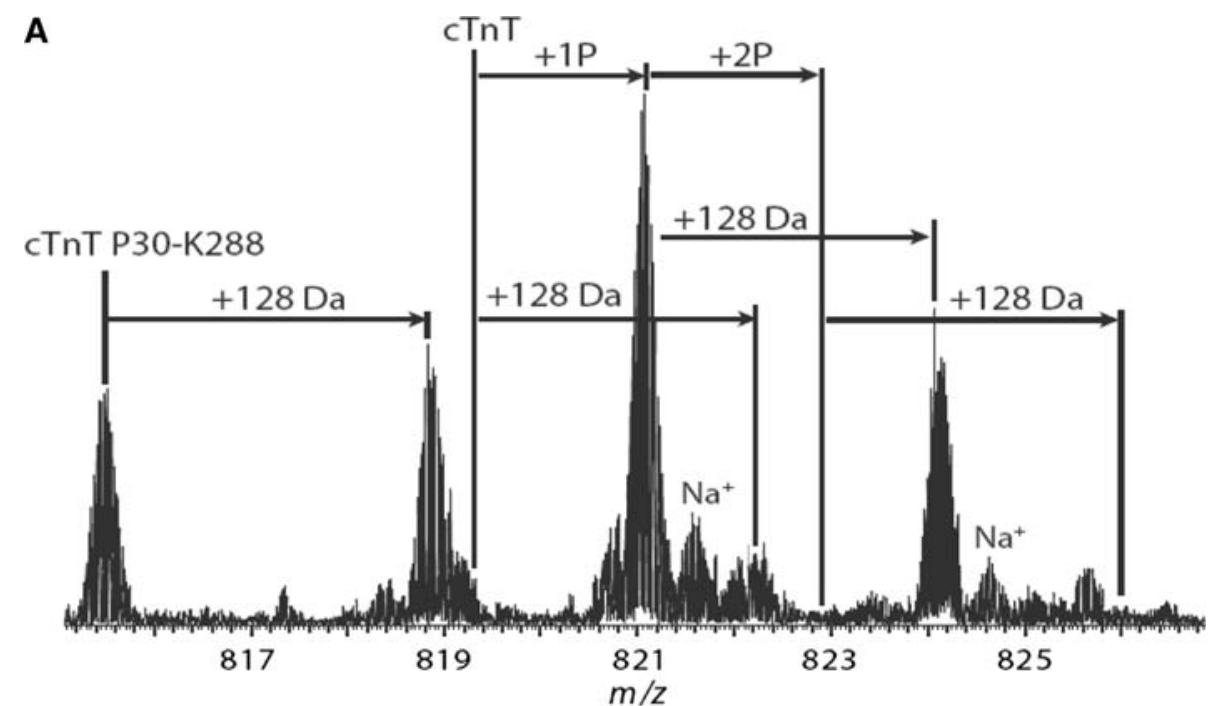

B

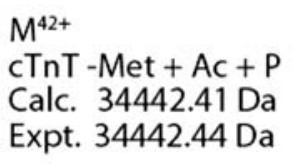

$\mathrm{M}^{38+}$

cTnT P30-K288

Calc. 30950.14 Da

Expt. 30950.17 Da

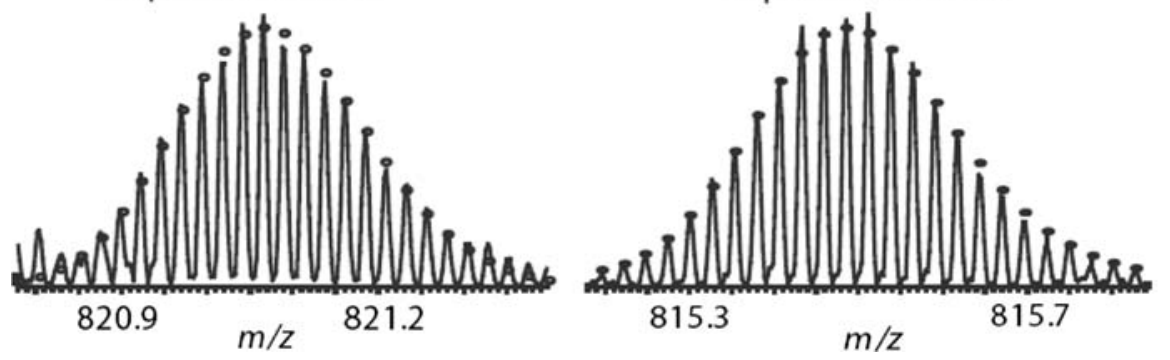

rapidly. Intriguingly, in such an arrangement, phosphoSer $^{22}$ may serve as a steady state indicator of the recent history of activation by $\beta$-stimulation and protein kinase $\mathrm{A}$, and would effectively serve to prime the system for more rapid onset of biological effects. One important difference between the rat cTnI results described here and the earlier results with human cTnI is that the human samples displayed a second prominent monophosphorylation site at $\mathrm{Ser}^{76}$ or $\mathrm{Thr}^{77}$ (Zabrouskov et al. 2008). This may reflect a limitation of the earlier study in which human cTnI, obtained commercially from Sigma-Aldrich or Calbiochem, was purified from mixtures of tissue obtained from multiple hearts. In contrast, the rat data described here were from single healthy rat hearts. The source of the human tissue is less well defined although company technical support believes it to be from 'healthy' human heart tissue.

Analysis of rat cTnT in the present study revealed its own unique forms of molecular heterogeneity. cTnT was observed to be predominantly monophosphorylated accounting for $90 \%$ of the intensity of full length cTnT in the mass spectra. We were unable to localize the monophosphorylation site(s) in rat cTnT with any precision, although ECD of cTnT-P did argue strongly against basal phosphorylation in the C-terminus downstream of residue 197 including Ser $^{198}$ and $\mathrm{Thr}^{203}$ which are putative PKC phosphorylation sites (Sumandea et al. 2003). Studies in a variety of animal species have established $\operatorname{Ser}^{1}$ of cTnT as a common phosphorylation site targeted by casein kinase 2 and often basally phosphorylated to near stoichiometric levels (Gusev et al. 1983; Risnik et al. 1985; Leszyk et al. 1987; Swiderek et al. 1990). Interestingly, the present data provided virtually no sequence information in the $\mathrm{N}$-terminal region of cTnT using either top-down analysis (i.e. no $c$-ions were observed) or bottom-up analysis (i.e. no N-terminal proteolytic peptides were detected). This may be a reflection of the unique composition of the N-terminus of cTnT which contains among its first 41 residues 25 acidic amino acids (Glu or Asp), no basic residues (Arg or Lys), and exhibits a strongly acidic $p \mathrm{I}$ (isoelectric point) of less than 3 . Thus, while the conditions employed in this study were not optimized for mass analysis of highly acidic peptides, and may have precluded the precise localization of the phosphoryl moiety in monophosphorylated cTnT, our data are consistent with constitutive phosphorylation of $\operatorname{Ser}^{1}$ in this species.

Considerable insight on this and other issues was provided by a detailed mass analysis of a prominent cTnT- 
Fig. 6 Localization of sequence heterogeneity in an endoprotease Glu-C peptide of cTnT. Peptides with masses that matched. a cTnT Ala ${ }^{173}-$ Glu $^{195}$ and b cTnT Ala ${ }^{173}$ -

$\mathrm{Glu}^{195}+128 \mathrm{Da}$ were isolated (insets), and subjected to sequence analysis by $\mathrm{CAD}$ fragmentation (upper and bottom panels). Peptide sequences are labeled with bonds cleaved and fragment ions detected

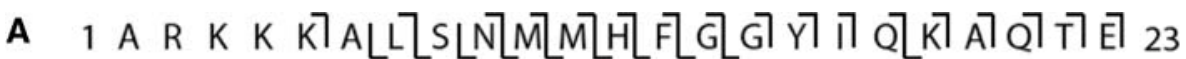

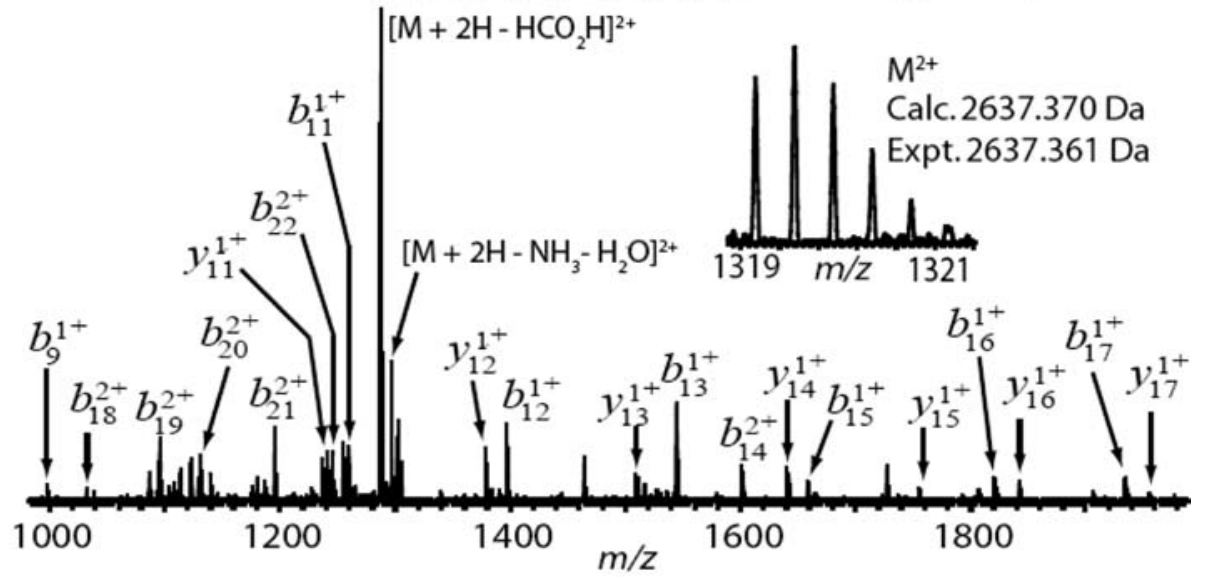

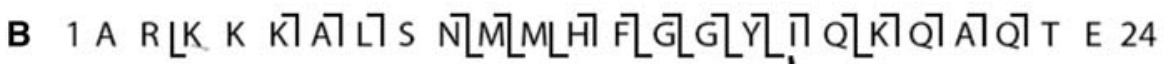

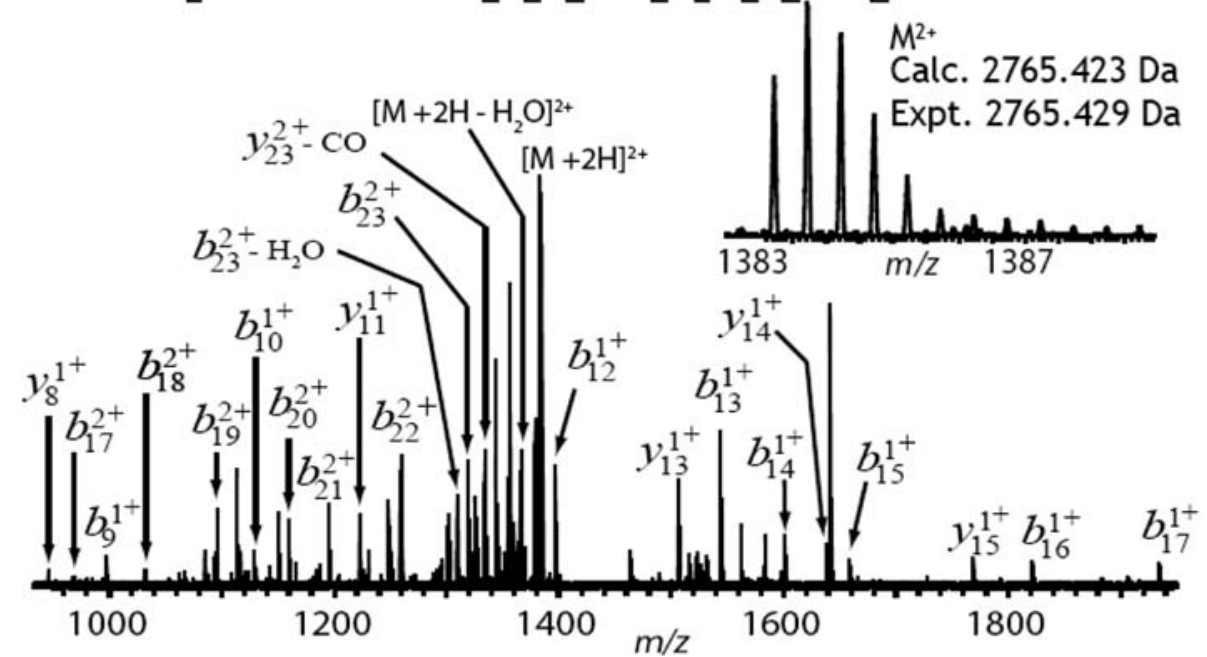

related species at 30,950.17 Da. Its mass matched with $<5 \mathrm{ppm}$ mass accuracy the predicted mass of a cTnT fragment containing residues 30-288; moreover, ECD generated a multitude of matching fragment ions covering both the N- and C-termini of this cTnT30-288 species. Importantly, the N-terminus of this version of cTnT was not acetylated suggesting that it arose from proteolysis of full length cTnT rather than via other transcriptional or translational mechanisms capable of generating protein diversity. Mass data of this quality and precision also virtually completely rules out the possibility that this cTnT species arose from an unusual or unknown mRNA splicing event, an important consideration for cTnT which can be extensively spliced (Biesiakecki et al. 2002). With regard to localization of phosphoryl moieties in cTnT-P, identification of cTnT30-288 also provided evidence for cTnT-P phosphorylation in the first 29 residues, as cTnT30-288 was consistently not phosphorylated.

In retrospect, proteolytic processing of cTnT as evidenced by the presence of cTnT30-288 is not surprising, as the highly acidic N-terminal domain is predicted to be disordered and unstable. cTnT has been shown to be proteolytically processed at its $\mathrm{N}$-terminus with pronounced effects on in vivo rat heart function (Feng et al. 2008). In that case, the predominant proteolytic event removed 71 residues from the N-terminus of cTnT compared to 29 residues observed here. A 26,400 Da fragment that could have arisen from removal of a 71 residue N-terminal domain was occasionally observed in our mass spectra, but only at very low levels that precluded further analysis by MS/MS fragmentation. A better understanding of mechanisms and consequences associated with proteolytic processing of the highly acidic N-terminal domain of cTnT will require further investigation.

A single amino acid variant at $+128 \mathrm{Da}$ was also detected for rat heart cTnT, with peak intensity representing approximately $40 \%$ of the total cTnT peak intensity in the spectra. A +128 Da variant was also associated with the cTnT30-288 proteolytic fragment of cTnT. Top-down and bottom-up analysis of cTn unequivocally localized this 
+128 Da difference to residue 192 of cTnT, a mass difference that could be due to the presence of an additional Gln or Lys at this location. Sequencing of genomic DNA clones of rat cTnT has revealed the presence of a $9 \mathrm{bp}$ exon (exon 12) that encodes a tripeptide Gln-Ala-Gln (Jin et al. 1992). Sequence analysis of cDNA clones further revealed that exon 12 is alternatively spliced in three ways: class I splicing retains the entire tripeptide in the sequence; class II splicing retains only Ala-Gln; and class III isoforms have the entire tripeptide spliced out. In that study, class II splicing was estimated to account for $\sim 80 \%$ of the cTnT protein expressed in rat heart (Jin et al. 1992). The most straight forward interpretation of the mass spectral data presented here is that the presence of $+128 \mathrm{Da}$ at residue 192 is due to class I splicing (inclusion of the entire tripeptide), whereas class II splicing would account for the peak lacking one Gln (-128 Da). According to this interpretation, class I splicing accounted for $\sim 40 \%$ of cTnT expressed in these Sprague-Dawley rat hearts, class II splicing (lacking Gln) accounted for $\sim 60 \%$ of cTnT expressed, and class III splicing with the entire tripeptide removed was undetected and thus not expressed at significant levels.

The functional significance of this splice heterogeneity remains to be determined, although it has been proposed that this region functions as a linker between distinct $\mathrm{cTnT}$ domains, namely the intrinsically disordered $\mathrm{N}$-terminal Tm binding domain and the cTnI binding cTnT1 domain (Harada and Morimoto 2004). Importantly, the present data clearly shows that heterogeneity in the length (and/or composition) of this putative linker occurs within a single rat heart. The present data were collected on combined right and left ventricular tissue of individual hearts, so whether or not this cTnT splice heterogeneity is distributed evenly throughout the heart remains to be explored. Analysis of molecular forms of cTnT within atrial versus ventricular tissues, from the right versus left heart chambers, or even transmurally across the ventricular walls may require improvements in methodology including enhanced mass spectrometer sensitivity and better protein recovery during purification and desalting.

Finally, it is of interest to determine how these single amino acid polymorphisms in cTn subunits alone or in combination might impact rat heart function. Understanding the $\mathrm{Ala}^{7} / \mathrm{Ser}^{7}$ polymorphism in $\mathrm{cTnI}$ may be more tractable as our methodology can be used to establish the 'genotype' of these rats at this locus. A systematic analysis of cardiac function prior to genotyping by isolation and mass spectrometry of cTn could be used to reveal functional differences between $\mathrm{Ala}^{7}$ and $\mathrm{Ser}^{7}$ variants, as well as to establish the properties of 'heterozygotes'. To evaluate the functional implications of the cTnT sequence variants, whose ratio does not appear to vary from animal to animal, may require in vitro functional assays in skinned muscles wherein the composition of cTn can be controlled by reconstitution or subunit exchange (Solaro 2008).

Acknowledgements The authors thank Dr. Andrew Messer and Professor Steven Marston for invaluable assistance with methods for affinity purification of troponin and for many helpful discussions. The authors also thank Christopher Doede, Jennifer Wachholz and Lisa $\mathrm{Xu}$ for expert technical assistance during early stages of the project. This work was supported by an American Heart Association Scientist Development Grant (YG), the Wisconsin Partnership for a Healthy Future, and NIH grant RO1 HL081386 (JWW).

Open Access This article is distributed under the terms of the Creative Commons Attribution Noncommercial License which permits any noncommercial use, distribution, and reproduction in any medium, provided the original author(s) and source are credited.

\section{References}

Biesiakecki BJ, Elder BD, Zhi-Bin Y, Jin JP (2002) Cardiac troponin $\mathrm{T}$ variants produced by aberrant splicing of multiple exons in animals with high instances of dilated cardiomyopathy. J Biol Chem 277:50275-50285. doi:10.1074/jbc.M206369200

Feng HZ, Biesdiadecki BJ, Yu ZB, Hossain MM, Jin JP (2008) Restricted N-terminal truncation of cardiac troponin T: a novel mechanism for functional adaptation to energetic crisis. J Physiol 586:3537. doi:10.1113/jphysiol.2008.153577

Ge Y, Lawhorn BG, ElNaggar M, Strauss E, Park JH, Begley TP, McLafferty FW (2002) Top down characterization of larger proteins $(45 \mathrm{kDa})$ by electron capture dissociation mass spectrometry. J Am Chem Soc 124:672-678. doi:10.1021/ja011335z

Gusev NB, Barskaya NV, Verin AD, Duzhenkova IV, Khuchua ZA, Zheltova AO (1983) Some properties of cardiac troponin T structure. Biochem J 213:123-129

Han XM, Jin M, Breuker K, McLafferty FW (2006) Extending topdown mass spectrometry to proteins with masses greater than 200 kilodaltons. Science 314:109-112. doi:10.1126/science.11 28868

Harada K, Morimoto S (2004) Inherited cardiomyopathies as a troponin disease. Jpn J Physiol 54:307-318. doi:10.2170/ jjphysiol.54.307

Jaffe AS, Babuin L, Apple FS (2006) Biomarkers in acute cardiac disease: the present and the future. J Am Coll Cardiol 48:1-11. doi:10.1016/j.jacc.2006.02.056

Jaquet K, Thieleczek R, Heilmeyer LM (1995) Pattern formation on cardiac troponin I by consecutive phosphorylation and dephosphorylation. Eur J Biochem 231:329-337. doi:10.1111/j.14321033.1995.tb20722.x

Jideama NM, Noland TA Jr, Raynor RL, Blobe GC, Fabbro D, Kazanietz MG, Blumberg PM, Hannun YA, Kuo JF (1996) Phosphorylation specificities of protein kinase $\mathrm{C}$ isozymes for bovine cardiac troponin I and troponin $\mathrm{T}$ and sites within these proteins and regulation of myofilament properties. J Biol Med 271:23277-23283

Jin JP, Huang QQ, Yeh HI, Ling JJC (1992) Complete nucleotide sequence and structural organization of the rat cardiac troponin $\mathrm{T}$ gene. J Mol Biol 227:1269-1276. doi:10.1016/0022-2836(92) 90540-Z

Keane NE, Quirk PG, Gao Y, Patchell VB, Perry SV, Levine BA (1997) The ordered phosphorylation of cardiac troponin I by the cAMP-dependent protein kinase: structural consequences and 
functional implications. Eur J Biochem 248:329-337. doi: 10.1111/j.1432-1033.1997.00329.x

Kelleher NL, Lin HY, Valaskovic GA, Aaserud DJ, Fridriksson EK, McLafferty FW (1999) Top down versus bottom up protein characterization by tandem high-resolution mass spectrometry. J Am Chem Soc 121:806-812. doi:10.1021/ja973655h

Kobayashi T, Yang X, Walker LA, Van Breemen RB, Solaro RJ (2005) A non-equilibrium isoelectric focusing method to determine states fo phosphorylation of cardiac troponin I: identification of Ser-23 and Ser-24 as significant sites of phosphorylation by protein kinase C. J Mol Cell Cardiol 38:213-238. doi:10.1016/j.yjmcc.2004.10.014

Leszyk J, Dumaswala R, Potter JD, Gusev NB, Verin AD, Tobacman LS, Collins JH (1987) Bovine cardiac troponin T: amino acid sequence of the two isoforms. Biochemistry 26:7035-7042. doi: $10.1021 / \mathrm{bi00396a027}$

Martin AF, Orlowski J (1991) Molecular cloning and developmental expression of the rat cardiac-specific isoform of troponin I. J Mol Cell Cardiol 23:583-588. doi:10.1016/0022-2828(91)90050-V

McLafferty FW, Horn DM, Breuker K, Ge Y, Lewis MA, Cerda B, Zubarev RA, Carpenter BK (2001) Electron capture dissociation of gaseous multiply charged ions by Fourier-transform ion cyclotron resonance. J Am Soc Mass Spectrom 3:245-249

Messer AE, Jacques AM, Marston SB (2007) Troponin phosphorylation and regulatory function in human heart muscle: dephosphorylation of $\mathrm{Ser}^{23 / 24}$ on troponin I could account for the contractile defect in end-stage heart failure. J Mol Cell Cardiol 42:247-259. doi:10.1016/j.yjmcc.2006.08.017

Murphy AM (2006) Heart failure, myocardial stunning and troponin: a key regulator of the cardiac myofilament. Congest Heart Fail 12:32-38. doi:10.1111/j.1527-5299.2006.04320.x

Nesviszhsii AI, Vitek O, Aebersold R (2007) Analysis and validation of proteomic data generated by tandem mass spectrometry. Nat Methods 4:787-797. doi:10.1038/nmeth1088

Pi YQ, Kemnitz KR, Zhang D, Kranias E, Walker JW (2002) Phosphorylation of troponin I controls cardiac twitch dynamics. Evidence from phosphorylation site mutations expressed on a troponin I null background in mice. Circ Res 90:649-656. doi: 10.1161/01.RES.0000014080.82861.5F

Pi YQ, Zhang D, Kemnitz KR, Wang H, Walker JW (2003) Protein kinase $\mathrm{C}$ and A sites on troponin I regulate myofilament $\mathrm{Ca}^{2+}$ sensitivity and ATPase rate in mouse myocardium. J Physiol 552:845-857. doi:10.1113/jphysiol.2003.045260

Risnik VV, Verin AD, Gusev NB (1985) Comparison of the structure of two cardiac troponin $\mathrm{T}$ isoforms. Biochem J 225:549-552
Sancho Solis R, Ge Y, Walker JW (2009) High resolution top-down MS/MS reveals single amino acid sequence polymorphisms in rat cardiac troponin. 2009 Biophysical Society Meeting Abstract, Biophys J, Supplement, Abstract

Senko MW, Speir JP, McLafferty FW (1994) Collisional activation of large multiply-charged ions using Fourier-transform mass-spectrometry. Anal Chem 66:2801-2808. doi:10.1021/ac00090a003

Siuti N, Kelleher NL (2007) Decoding protein modifications using top-down mass spectrometry. Nat Methods 4:817-821. doi: $10.1038 /$ nmeth 1097

Solaro RJ (2008) Multiplex kinase signaling modifies cardiac function at the level of sarcomeric proteins. J Biol Chem 283:2682926833. doi:10.1074/jbc.R800037200

Sumandea MP, Pyle WG, Kobayashi T, de Tombe PP, Solaro RJ (2003) Identification of a functionally critical protein kinase $\mathrm{C}$ phosphorylation residue of cardiac troponin T. J Biol Chem 278:35135-35144. doi:10.1074/jbc.M306325200

Swiderek K, Jaquet K, Meyer HE, Schachtele C, Hofmann F, Heilmeyer LM (1990) Sites phosphorylated in bovine cardiac troponin $\mathrm{T}$ and I. Characterization by 31P-NMR spectroscopy and phosphorylation by protein kinases. Eur $\mathbf{J}$ Biochem 190:575-582. doi:10.1111/j.1432-1033.1990.tb15612.x

Vahebi S, Kobayashi T, Warren CM, de Tombe PP, Solaro RJ (2005) Functional effects of rho-kinase-dependent phosphorylation of specific sites on cardiac troponin. Circ Res 96:740-747. doi: 10.1161/01.RES.0000162457.56568.7d

Wang H, Grant JE, Doede CM, Sakthivel S, Robins J, Walker JW (2006) PKC-betaII sensitizes cardiac myofilaments to $\mathrm{Ca}^{2+}$ by phosphorylating troponin I on threonine-144. J Mol Cell Cardiol 41:823-833. doi:10.1016/j.yjmcc.2006.08.016

Yates LD, Greaser ML (1983) Troponin subunit stoichiometry and content in rabbit skeletal muscle and myofibrils. J Biol Chem 258:5770-5774

Zabrouskov V, Ge Y, Schwartz J, Walker JW (2008) Unraveling molecular complexity of phosphorylated human cardiac troponin I by top down electron capture dissociation/electron transfer dissociation mass spectrometry. Mol Cell Proteomics 7:18381849. doi:10.1074/mcp.M700524-MCP200

Zhang R, Zhao J, Potter JD (1995) Phosphorylation of both serine residues in cardiac troponin $\mathrm{I}$ is required to decrease the $\mathrm{Ca}^{2+}$ affinity of cardiac troponin C. J Biol Chem 270:30773-30780. doi:10.1074/jbc. 270.51 .30773 